\title{
Analysis of the Evacuation Capacity of Parallel Double Running Stairs in Different Merging Form Based on Simulation
}

\author{
Xia-zhong Zheng $\mathbb{D}^{1},{ }^{1,2}$ Xue-ling Xie, ${ }^{1,2}$ Dan Tian $\mathbb{D}^{1,},{ }^{1,2}$ Jian-lan Zhou $\mathbb{D}^{3}{ }^{3}$ and Ming Zhang ${ }^{1,2}$ \\ ${ }^{1}$ China Three Gorges University, College of Hydraulic \& Environmental Engineering, Yichang 443002, China \\ ${ }^{2}$ China Three Gorges University, Hubei Key Lab Construct \& Management Hydropower E, Yichang 443002, China \\ ${ }^{3}$ Huazhong University of Science \& Technology, Ministry of Education, Key Lab of Image Processing \& Intelligent Control, \\ Wuhan, Hubei 430074, China
}

Correspondence should be addressed to Dan Tian; 2423450107@qq.com

Received 27 November 2017; Accepted 2 July 2018; Published 15 July 2018

Academic Editor: Cengiz Çinar

Copyright (C) 2018 Xia-zhong Zheng et al. This is an open access article distributed under the Creative Commons Attribution License, which permits unrestricted use, distribution, and reproduction in any medium, provided the original work is properly cited.

\begin{abstract}
In order to analyze the evacuation capacity of parallel double running stairs, a dozen stairs merging forms are set by investigation and statistics, and the improved agent-based evacuation model that considers the merging behavior is used to simulate the process of merging and evacuation in the stairs. The stairs evacuation capacity is related to the evacuation time and the robustness of stairs, and the evacuation time can be calculated by using the improved agent-based model based on computer simulation. The robustness of each merging form can be obtained according to the fluctuation degree of evacuation time under the different pedestrian flow. The evaluation model of stairs evacuation capacity is established by fusing the evacuation time and the robustness of stairs. Combined with the specific example to calculate the evacuation capacity of each stairs form, it is found that every merging form has different evacuation time and different robustness, and the evacuation time has not positive correlation with the robustness for the same form stairs. Meanwhile, the evacuation capacity of stairs is not related to the number of the floor entrances. Finally, the results show that the evacuation capacity of stairs is optimal when the floor entrances are close to out stairs in parallel double running stairs and suitable to the case where pedestrian flow and the change of pedestrian flow are large.
\end{abstract}

\section{Introduction}

Stairs are one of the most important components for the safe egress of occupants in high-rising buildings or underground buildings in case of fire emergency [1]. In recent years, stairs accidents occur frequently due to the congestion in stairs evacuation, which have caused a large number of injuries, even death, and make the stair channels become public security hidden danger; what is more, it creates huge social panic [2].

In May 2010, in New Delhi, India, stairs trample accident occurred at the railway station, where two people died and five people wounded. Morning of November 17, 2006, congestion accident of one hundred of high school students occurred when they walked down stairs and 12 students got injured due to extrusion in Xian Yang Second Primary Middle School. Late November 18, 2006, the students in Jiang Xi Middle School were injured when they went down stairs in the night lessons because of the congestion. In the process of evacuation stairs, if there is a single flow of occupants, it will not produce the great congestion in evacuation stairs process. Occupants merging can lead to the increase of original pedestrian flow rate and cause occupants evacuation behavior and the principle of the occupants movement to change, and stairs congestion phenomenon will produce [3]. Therefore, the occupants merging is one of the important factors that causes congestion phenomenon in the process of stairs evacuation. It is significant to alleviate the pressure of the stairs evacuation and reduce the number of channel traffic accidents by researching evacuation ability in different merging form stairs.

Stairs play an important role in building evacuation since it is generally the only way to evacuate occupants [4]. Many evacuation methods, such as network modeling [5], affordance-based finite state automata (FSA) modeling [6], cellular automaton models [7, 8], lattice-gas models [9], 
floor field models [10], and finer discrete models [11], have been proposed to study the characteristics of occupants' evacuation. These studies play important roles in predicting pedestrian behavior during evacuation and in designing evacuation facilities [12].

Over the past decade, occupants' movements on stairs have attracted a lot of researchers to study in order to make the process of evacuation as fast as possible and reduce stairs congestion [13]. When studying the evacuation of buildings, some researchers found that stairs evacuation is part of the evacuation of high-rise buildings, which has great significance in the whole evacuation process [14]. As the research deepens, the stairs evacuation is gradually separated from the building evacuation as a separate research object, the researchers explore the impact of stairs evacuation on the whole evacuation process. For stairs evacuation, researchers mainly study from two aspects: one is from stairs design, and the other is the evacuation behavior of occupants.

From the aspects of stairs designing, the effect of the design of the stairs for evacuation time is studied by changing the geometric parameters of the stairs. Some researchers considered the stairs width; by simulating different width of the stairs, they got the relationship between stairs' width and the evacuation time [15]. Finally, the optimal width of stairs was obtained. The influence factors of evacuation stairs were analyzed from the perspective of physical. However, person is the main object of stairs evacuation. Occupants' behaviors will have a huge impact on the result of the evacuation in the process of actual evacuation. Therefore, it is of great relevance to analyze the relationship between human behavior and evacuation time.

From the perspective of human beings, some researchers thought that the occupants age could influence the result of evacuation; therefore, analyzing the evacuation situation of the elder and children is important to research the influence degree of occupants age [16-18]. In addition to the difference of age, there are many factors in the process of evacuation. Generally speaking, the sex ratio of the occupants may also affect the result of evacuation; the difference of sex will lead to the change of movement speed and movement path of the evacuation [1]. Meanwhile, the fatigue degree of occupants should be considered during stairs evacuation [19]. However, the occupant's behavior does not give a specific illustration. Therefore, Yun Chao Qu proposed an enhanced social force model to describe the occupant movement and evacuation dynamics on the stairs [20]. In addition to the factors in the social force model, the preference between occupants is considered as a factor in respect of affecting evacuation [21]. Meanwhile, Yi ping Zeng studied the human movement characteristics and human behavior performance and got that the selection preferences of personnel would also change when the surrounding environment changes [13]. In summary, factors such as physical exertion and behavior change will influence the walking speed and ultimately influence the process of evacuation [22].

These studies have stated the influence of physical factors and human factors on stairs evacuation time from multiple aspects. However, they did not consider the occupants merging behavior on the stairs. Therefore, Tomonori believed that the stairs evacuation process includes the process of occupants merging, and the merging rate is introduced to calculate the time of merging, and finally the evacuation time of the building is obtained [3]. There were many merging forms of stairs evacuation, but Tomonori only gave one kind of merging form of stairs evacuation and did not analyze the other merging form. Therefore, Galea examined the nature of the merging process at the floor-stairs interface and got the merging behavior by comparing two kinds of staircase form [23]. However, Galea neglected other stairs merging form and did not research the evacuation ability of the stair.

Through analyzing the process of the stairs evacuation, it is obvious that the occupants' behavior is important to the result of evacuation [3]. Therefore, it is necessary to choose an accurate model which can reflect the occupants' merging behavior. Jian yong Shi thought the occupant movement is defined by environment driving and established the agentbased evacuation model [24]. V. Dossetti used the agentbased model to analyze the human behavior and proved the feasibility of the agent-based model [25]. Meanwhile, Jaekoo Joo adopted agent-based model to establish a human behavior framework and verified the accuracy of agentbased model [6]. However, these studies did not consider the merging behavior in the stairs evacuation. It is necessary to establish a new model that takes merging behavior into account in stairs evacuation.

To sum up, in the evacuation process of the stairs, the merging behavior should be considered. Meanwhile, the evacuation ability of stairs should be analyzed. In this paper, we propose a novel agent-based evacuation model that considers the merging behavior. According to the criterion of stairs design, we set 12 kinds of parallel double running stairs by different merging forms. In order to make the evacuation time more accurate, the agent-based model of the merging behavior is adopted to express the process of stairs evacuation. The evacuation ability of stairs is affected not only by the evacuation time but also by the robustness of stairs; thus, the robustness is calculated by changing the pedestrian flow rate in each floor. According to the evacuation time and the robustness of stairs, the evacuation ability of stairs evaluation model is established, and the optimal merging form of stairs can be obtained by calculating the evacuation ability of stairs.

The remainder of this paper is organized as follows. In Section 2, the improved evacuation model that considers merging is introduced. The different merging forms and evacuation capacity evaluation model are established in Section 3. The specific example is used to analyze the various merging forms of stairs in Section 4. Section 5 is mainly a discussion of simulation results. Finally, the conclusions and the further work are given in Section 6.

\section{Pedestrian Evacuation Model on Stair}

2.1. Model Assumption. A set of assumptions need to be introduced in order to explain the field of applicability of the model before the model is established. Many scholars adopt these assumptions to analyze the pedestrian evacuation [3]. 
Assumption 1. The pedestrian merging in the stairs is continuous and there is no delay in the process of merging on stairs [26]. In general, the evacuation is a continuous process without any restriction; thus the merging is not interrupted in the evacuation process.

Assumption 2. The width of stairs is steady, and according to the principle of the stairs design, the width of stairs is uniformly valued. According to the design criterion of staircase, the width of stairs is set as constant value [27].

Assumption 3. The initial conditions are assumed that the stairs are filled with occupants and have the same density in each stair. The capacity of stairs is the stairs evacuation effect in the extreme environment, only in this way is this study significant.

Assumption 4. Each stair's merging ratio and the floor's merging ratio are fixed value, which will not change over time [3].

Assumption 5. The inclination of the stairs should not be more than $45^{\circ}$.In general, it is defined as $30^{\circ}$, and the number of stairs steps is set as $18^{\circ}$ [27].

Assumption 6. No pedestrians come from the ground floor. In the process of evacuation, the pedestrian movement object is structure exit. Thus, there is no pedestrian coming from the ground floor.

Assumption 7. The form of stairs in this paper studies parallel double running. In general, the stairs in the building are designed to parallel double running stairs by the investigations of different populations and stair configurations.

2.2. Agent-Based Evacuation Model. In accordance with the existing design methods, there are many staircases structures including straight stairs structure and parallel double running stairs structure, wherein the parallel double running stairs structure is widely adopted [28]. In general, the pedestrian must change their movement directions in the floor platform according to the structure of parallel double running stairs; the evacuation process of pedestrian is complex [29]. Thus, the agent-based evacuation model is adopted to analyze the evacuation process of parallel double running stairs [6].

The agent decision model is constructed through the integration of intelligent simulation methods including agent technology and rule reasoning. As a representation of pedestrians, the agents make decisions on behavior at each time instant according to certain rules. They search for corresponding rules with the change of environment so as to adjust themselves in the agent-based model, in order to better express the behavior of the occupants, and to reflect the interaction form of occupants; the occupants evacuation model, which contains a grid matrix $M$ and the agents information sets $A(t)$, is defined as $S$. It is formulated in the following mathematical model:

$$
S=\{A(t), M\}
$$

$M$ is rectangular coordinate system; in this system, the points in space can be positioned by using the coordinate information; the position of occupants can be accurately reflected at any time. The scale of $M$ is defined as

$$
M=\left\{(x, y) \mid x_{\min } \leq x \leq x_{\max }, y_{\min } \leq y \leq y_{\max }\right\}
$$

$(x, y)$ is the coordinate position of occupants; $x_{\text {min }}, x_{\text {max }}$, $y_{\text {min }}, y_{\text {max }}$ are the boundaries of evacuation scale.

Usually, three different interactions are considered during stairs evacuation: interactions among occupants, interaction between occupants and buildings, and interaction between occupants and environment [24]. These interactions will affect decision-making and behaviors of occupants. In the process of stairs evacuation, the interactions can be shown by the occupants' behavior. Therefore, we use the behavior driving instead of interactions driving. According to the requirements of the agent-based evacuation model, we define agents information sets $A(t)=\left(a_{1}(t), a_{2}(t) \cdots a_{n}(t)\right)$, where $n$ represents the number of occupants. There is much information about each pedestrian during the process of stairs evacuation; we define the position of occupants sets $L(t)=\left(l_{1 t}, l_{2 t} \cdots l_{n t}\right)$, where $l_{k t}$ is the position of $k t h$ occupant at time $t$. At random time $t$, the $k$ th occupant's information can be defined as

$$
a_{k}(t)=\left(l_{k t}, v_{k t}, C_{k t}\right)
$$

$v_{k t}$ is the velocity; $C_{k t}$ is the behavior driving factor.

Stairs evacuation is a complicated decision-making process; occupants who need to be evacuated will constantly adjust the movement behavior according to the change of environment and make a reasonable judgment. The traditional agent-based model does not refer to specific behavior [6] and omits the importance of merging behavior. Based on current agent-based model, the merging behavior is considered in the behavior driving factor. According to the character of merging, the merging behavior can be divided into 9 kinds of stairs evacuation behaviors.

The merging behavior includes the seek behavior $C_{\text {seek }}$ [30], the avoid occupants behavior $C_{a o}$ [7], the idle separate behavior $C_{\text {isep }}$ [31], the avoid walls behavior $C_{a w}$ [32], the seek separate behavior $C_{\text {ssep }}$ [33], the seek wall separate behavior $C_{\text {swsep }}$ [34], the lanes behavior $C_{\text {lanes }}$ [35], the pass behavior $C_{\text {pass }}$ [11], and the cornering behavior $C_{c n r}$ [36]. Combining the merging behavior, the behavior driving factor can be described as

$$
\begin{aligned}
C_{k t}= & w_{1}^{k t} C_{\text {seek }}+w_{2}^{k t} C_{\text {isep }}+w_{3}^{k t} C_{a w}+w_{4}^{k t} C_{a o} \\
& +w_{5}^{k t} C_{\text {ssep }}+w_{6}^{k t} C_{\text {swsep }}+w_{7}^{k t} C_{\text {lanes }}+w_{8}^{k t} C_{\text {pass }} \\
& +w_{9}^{k t} C_{c n r} \quad(k=1,2 \ldots n)
\end{aligned}
$$

$C_{\text {seek }}$ represent the seek behavior; the seek behavior steers the occupants to travel along a seek curve. $C_{a o}$ represents the avoid occupants behavior; the avoid occupants behavior steers the occupants to avoid collisions with other occupants. $C_{i s e p}$ represents the idle separate behavior; the idle separate behavior steers occupants to maintain a desired distance away 
from other occupants and is used when occupants are in an idle state. $C_{a w}$ represents the avoid walls behavior; the avoid walls behavior detects walls and steers the occupants to avoid collisions with them. $C_{\text {ssep }}$ represents the seek separate behavior; the seek separate behavior spreads out occupants to maximize their travel speed as calculated by the occupant's speed-density curve. $C_{\text {swsep }}$ represents the seek wall separate behavior; the seek wall separate behavior steers occupants such that they want to maintain a boundary layer distance away from walls. $C_{\text {lanes }}$ represents the lanes behavior; the lanes behavior steers occupants into lanes when they detect that they are in counter flow with other occupants. It works by steering occupants toward the center of mass of the occupants in front who are not in counter flow. $C_{\text {pass }}$ represents the pass behavior; the pass behavior steers occupants so that they prefer to walk behind faster moving occupants. $C_{c n r}$ represents the cornering behavior; the cornering behavior seeks to steer agents so that they can take wide turns as part of a group without cutting in front of each other. $w_{q}^{k t}(q=1,2, \ldots, 9)$ is the decision variable of $k$ th occupants for $q$ th behavior at time $t$; the value is 0 or 1 . If $w_{q}^{k t}=1$, the occupants choose the $q$ th behavior; if $w_{q}^{k t}=0$, the occupants do not choose $q$ th behavior; the value of $w_{q}^{k t}$ depends on the environment that person locates. $k$ represents $k$ th occupants in the process of evacuation.

In the SFPE Handbook of Fire Protection Engineering, the relationship between speed $v$ and density $\mathrm{D}$ is denoted as [13]

$$
v(D)= \begin{cases}u-0.266 \times u \times D & D>0.54 \\ v_{\max } & D \leq 0.54\end{cases}
$$

$v_{\max }$ is the maximum speed for personnel, that is, $v_{\max }=$ $1.2 \mathrm{~m} / \mathrm{s}, u$ is velocity coefficient, when people locate in the horizontal plane, $u=1$. When people locate on the stairs, $u=1$, $D$ is occupants density.

Through analyzing (5), the velocity of occupants decreases as the occupants density increases. Meanwhile, the position of occupants at time $t+1$ is determined by the merging behavior, velocity, and position of occupants at time $t$. Therefore, the process of evacuation can be regarded as a constant iterative process, which refers to the merging behavior, velocity, and position of occupants; the iteration process does not end until the occupants reach the exit of construction, and the iterative function can be defined as

$$
l_{t+1}=f\left(l_{t}, v_{t}, C_{t}\right)
$$

When the position of occupants broke away from the scale of $M$, that is, $l_{t} \notin M$, the iteration will be terminated, and the time $t$ is the final evacuation time.

\section{Calculation of the Evacuation Capacity of Different Merging Form}

3.1. Merging Form. The stairs include incoming stair, out stair, stairs platform, floor platform, and floor entrance, as shown in Figure 1.

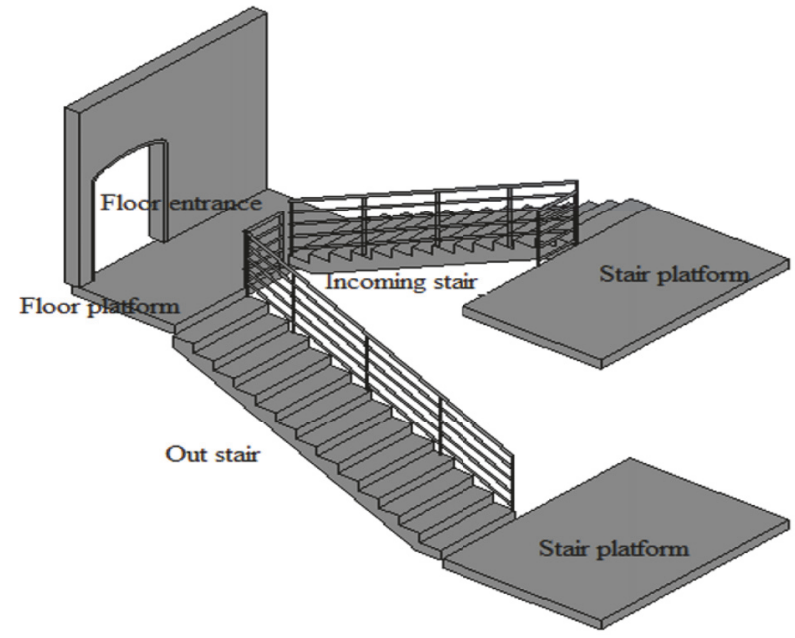

FIGURE 1: The structure and structure name of the stairs.

In the apartment, the stairs are usually designed as the parallel double running which include only one floor entrance in each floor. Thus, the merging form of the occupants is determined by the pedestrian flow of stairs and the pedestrian flow of the floor entrance. The floor flow enters the floor platform through the entrance of the staircase. When the relationship of the space between the floor entrance and the incoming stairs changes, the merging form of stairs will also change. Therefore, the relationship of space position between the floor entrance and incoming stairs decides the stairs merging form. The incoming stairs are taken as the reference frame, and the merging form between the stairs population and floor population is established by changing position where the floor pedestrian flow enters the stairs. We investigated 200 stair structures of apartments in China and extracted five kinds merging forms according to the position difference of floor entrance, which are shown as in Figure 2.

In Figure 2, there are five basic merging types: typel describes the incoming stairs close to floor entrance (Figure 2(a)); type2 represents the incoming stairs that are opposite to the floor entrance (Figure 2(b)); type3 describes the floor entrance that is located in the middle of the floor platform (Figure 2(c)); type4 denotes the out stairs that face toward the floor entrance (Figure 2(d)); type5 expresses the floor entrance that is close to out stairs (Figure 2(e)).

For complex structure, such as library, classroom building, and megastore, one entrance does not meet the requirement of evacuation. Thus, there is more than one entrance, and the design form of stairs is not limited to the above 5 types. There are the changes of the merging form showing more the way which the floor pedestrian flow enters stair; the main expression of way is the change of the number and position of floor entrances. To assure that all merging forms can be considered, we set three investigation fields which include school, megastore, and other structures and collect 50 typical structures for each field. Finally, we obtain 7 kinds of merging forms, which can be described as in Figure 3.

Unlike the merging form in Figure 2, these merging forms are designed by the requirement of structure rather 


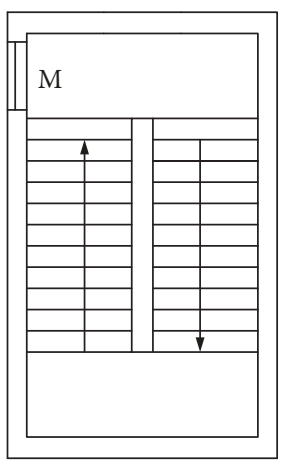

(a)

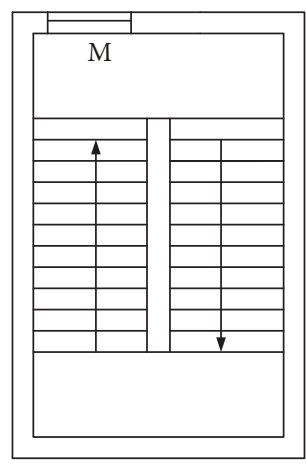

(b)

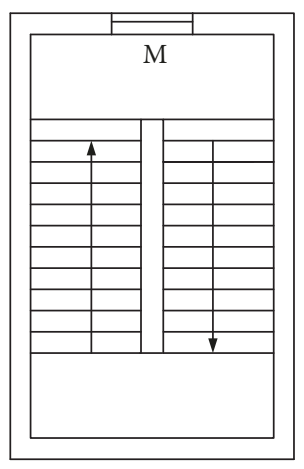

(c)

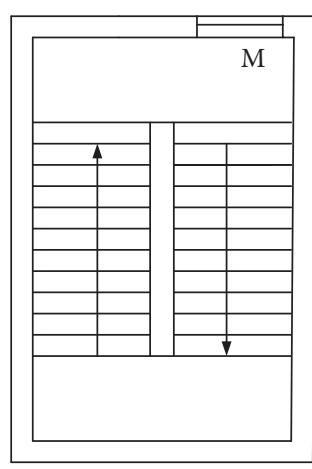

(d)

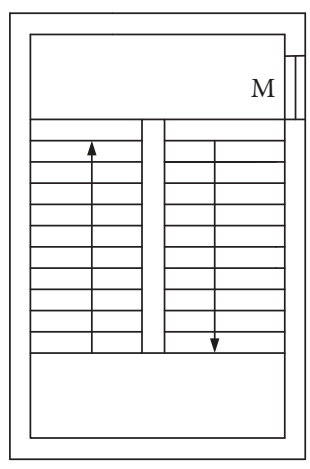

(e)

FIGURE 2: The merging form of stairs when there is one floor entrance and the floor entrance is set in different positions.

than the combination of merging form in Figure 2, and the floor entrance is set according to the evacuation character of pedestrian flow rate. Type6 describes that the one floor entrance is adjacent to the incoming stair, and the other floor entrance faces toward incoming stair (Figure 3(a)); type7 represents that one floor entrance is adjacent to the out stair, and the other floor entrance faces toward the incoming stair (Figure 3(b)); type8 describes that one floor entrance is adjacent to the out stair, and the other floor entrance is adjacent to the incoming stair ((Figure 3(c))); type9 describes that the one floor entrance is adjacent to the out stairs, and the other floor entrance faces toward incoming stair $(($ Figure 3(d))); type10 describes that one floor entrance is adjacent to the out stair, and the other floor entrance faces toward the out stair ((Figure 3(e))); there are three floor entrances in type1l, and the one floor entrance faces toward the incoming stairs, and the other respectively is close to the incoming stairs and out stairs (Figure 3(f)); unlike type11, in type12, the one floor entrance faces toward the out stair, and the other respectively is close to the incoming stairs and out stairs (Figure 3(g)).

3.2. The Evacuation Capacity Evaluation Model. The ability of the stairs evacuation is analyzed mainly including two aspects: one is the staircase evacuation time and the other is the robustness of the staircase evacuation. The different pedestrian flow rate is simulated to explore the ability of the stairs evacuation, and the evacuation time $t_{r}$ is obtained in each pedestrian flow rate. By simulating each type of stairs merging, evacuation time $t_{r j}(j=1,2 \ldots 12)$ can be got, where $j$ represents the merging form and $r$ is the group of pedestrian flow rate.

By comparing the stairs evacuation time, the evacuation ability of different merging form can be observed. When the flow rate is constant, the shortest evacuation time is $T_{r}$ in all merging forms; $T_{r}$ is defined as

$$
T_{r}=\min _{j=1}^{12}\left(t_{r j}\right)
$$

The stairs have frequently the change of flow rate as an important part of the building evacuation. Therefore, the sensitivity of stairs for the changes of flow rate is also an important indicator, which can be adopted to evaluate the ability of stairs; we use the robustness of stairs to represent the sensitive degree of pedestrian flow rate. The robustness of stairs refers to the fluctuation of the staircase evacuation time when the pedestrian flow rate changes. Stairs robustness is defined as

$$
\begin{aligned}
\Delta t_{j} & =\sum_{r=1}^{m} \frac{\left(t_{r j}-\overline{t_{j}}\right)^{2}}{m} \\
\varphi_{j} & =\frac{1}{\Delta t_{j}}
\end{aligned}
$$

$\Delta t_{j}$ is the fluctuation of $j$ th merging form, $\varphi_{j}$ denotes the robustness of $j$ th merging form, $\overline{t_{j}}$ represents the mean of each pedestrian flow rate of evacuation time, that is, $\overline{t_{j}}=\sum_{r=1}^{m} t_{r j} / m, m$ is the number of groups, and there are differences of pedestrian flow rate in each group.

The evacuation time and the robustness of stairs are important indicators which influence the ability of the stairs evacuation. However, when we evaluate the ability of stairs evacuation, it does not guarantee the consistency between stairs evacuation time and the robustness of the stairs, and it will occur a situation that the robustness is not optimal when the evacuation time is optimal. Aiming at this case, the evacuation ability of stairs evaluation model is established by fusing the evacuation time and the robustness of stair; the formula is defined as

$$
I_{j}=\frac{\alpha}{\widehat{t}_{j}}-\beta \times \varphi_{j}
$$

$\widehat{t}_{j}$ represents the mean of evacuation time in the $j$ th merging form after the dimensionless treatment, that is, $\widehat{t}_{j}=$ $\sum_{r=1}^{m}\left(t_{r j} / T_{r}\right) / m . \alpha, \beta$ are the degree of importance of stairs evacuation time and robustness, that is, $\alpha+\beta=1$. The value of $\alpha, \beta$ can be determined according to the specific problem [3]. $I_{j}$ represents the capacity of $j$ th merging form of stair.

\section{Case Study}

In order to get more accurate and fast evacuation results, a lot of the simulation software programs have been applied 


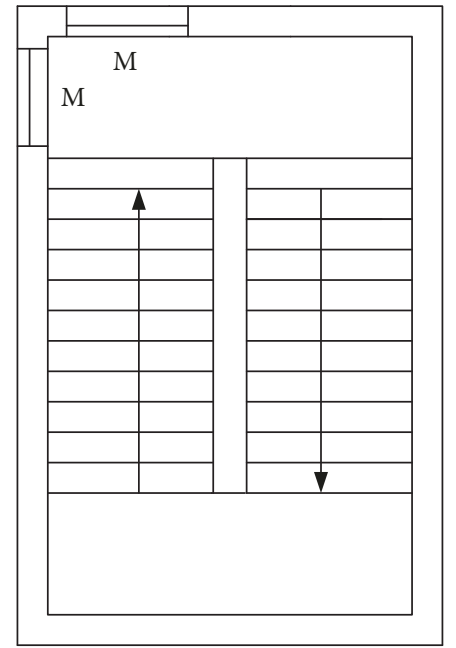

(a)

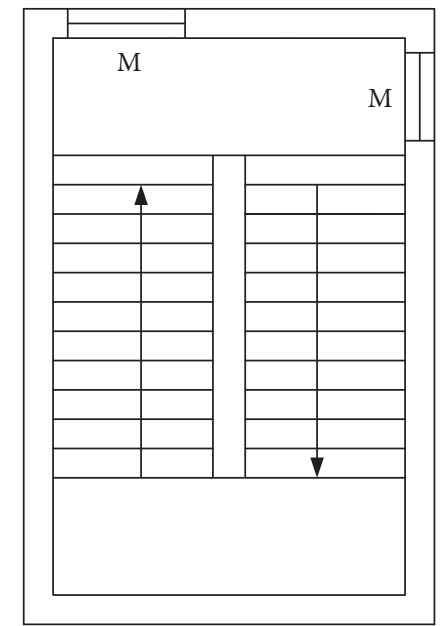

(d)

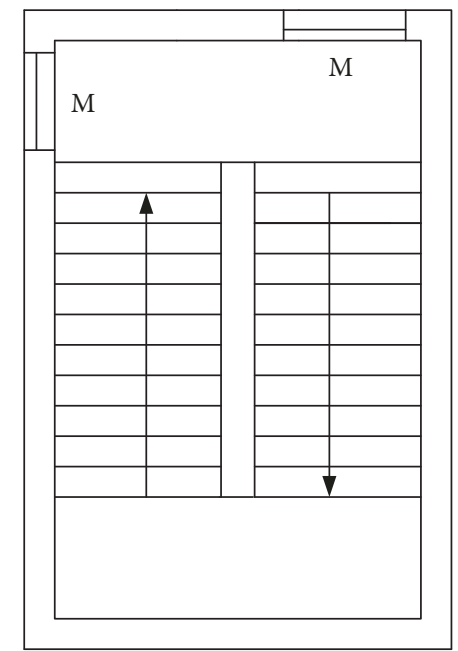

(b)

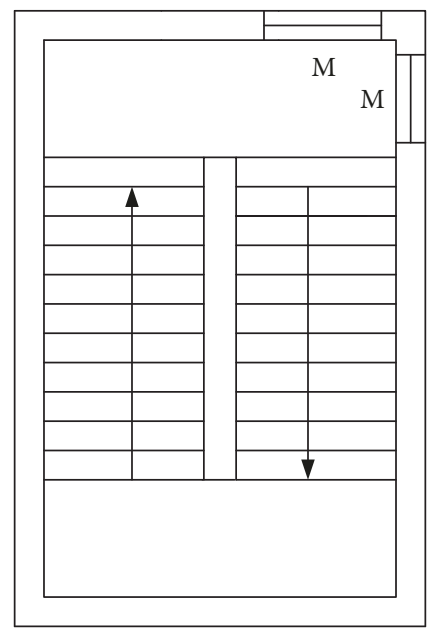

(e)

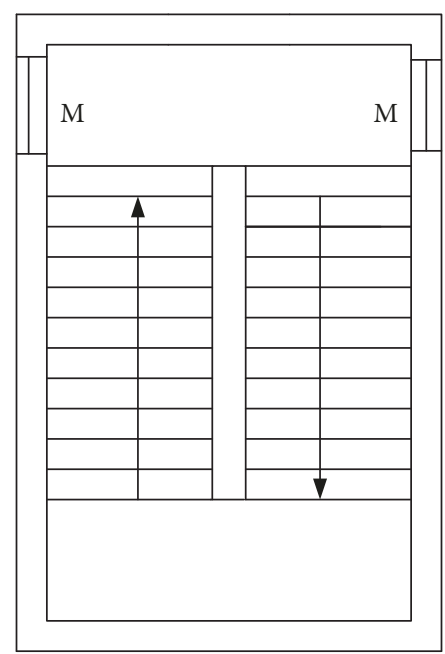

(c)

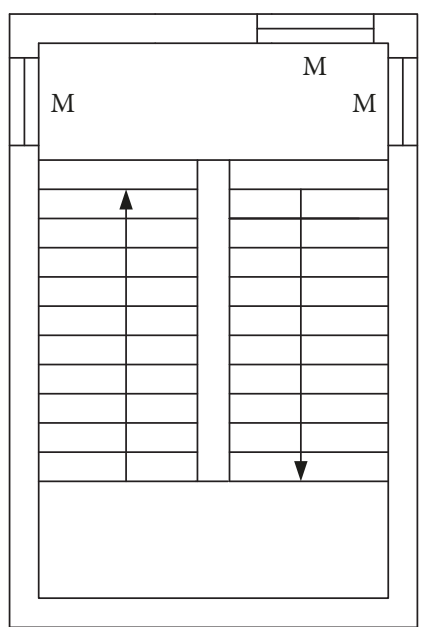

(f)

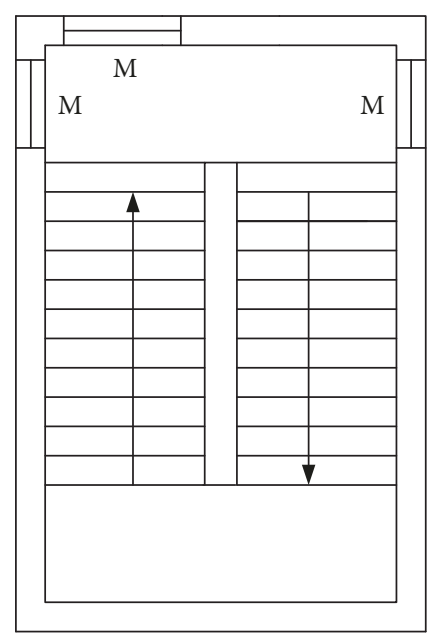

(g)

FIGURE 3: The merging form of stairs when there are more than one floor entrance and the different combination of floor entrances. 


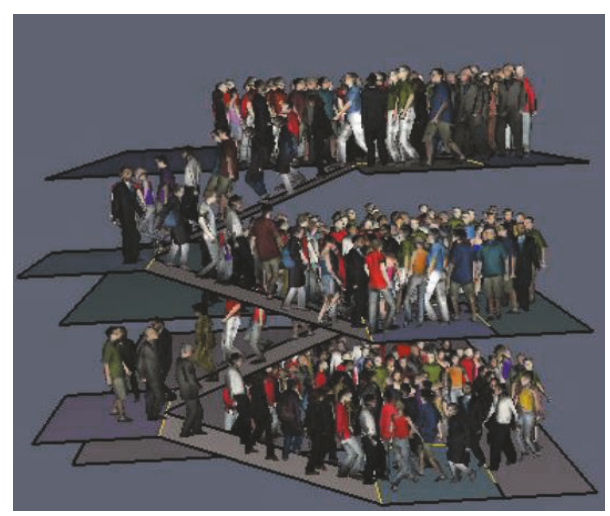

(a)

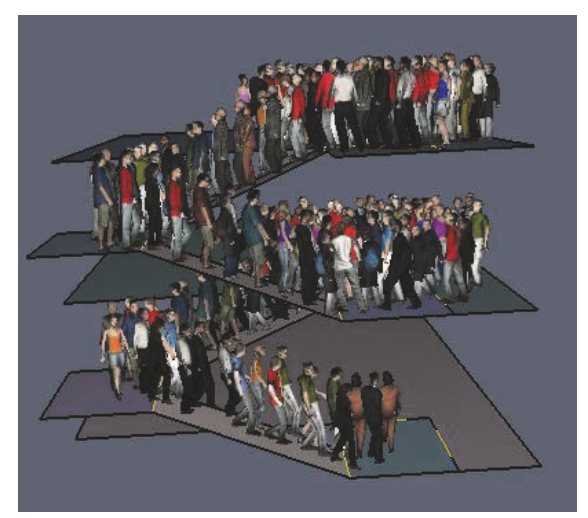

(b)

FIGURE 4: The occupants evacuation status at different time for type3. (a) Occupants evacuation status at 100s; (b) occupants evacuation status at 200 s.

in the process of the occupant evacuation, such as the FDS, Anylogic, and Pathfinder [12]. According to the evacuation model, we can select the corresponding simulation software. In this paper, we chose Pathfinder to simulate the stairs evacuation. Pathfinder software is the simulator of the agentbased model [37], which can accurately reflect the behavior of occupants in the evacuation process.

Taking a school teaching building as the background, the floor height is $3 \mathrm{~m}$, a total of three layers, including two stairs platforms, three floor platforms, stairs width of $1.5 \mathrm{~m}$, step width of $25 \mathrm{~cm}$, and kicking height to $20 \mathrm{~cm}$; each floor platforms head is $3.3 \mathrm{~m}$, width is $2 \mathrm{~m}$, and floor channel width is $1.5 \mathrm{~m}$.

The evacuation time of each type of merging is calculated by simulating. The effective area of floor in each merging is equal, and the occupants are distributed evenly on the floor; that is, every occupant has equal floor occupancy rate. For each floor, the ratio of female and male is 1:1; the evacuation processes are shown as in Figure 4.

In Figure 4(a), the distribution of occupants in space is the initial state, and the 50 people are distributed evenly in space according to the floor area. Figure 4(b) indicates the occupant's evacuation behavior and the service principle of occupants when the merging occurs on the floor platform in the case of type 3 of merging form.

To verify the accuracy of the simulation results, in this paper, the staircase evacuation investigation is carried out in a teaching building; its merging form is satisfied with the condition of type3. The survey shows that there are 50 students in each layer of the teaching building, during the peak of the evacuation; 50 students are downstairs and produce the congestion in the floor; occupants evacuation processes are shown as in Figure 5.

The teaching building evacuation time is investigated, and we get 5-group time value in the peak of evacuation. By comparing the statistical data and simulated data, the error between the simulation time and the actual evacuation time is obtained, as shown in Figure 6.

In Figure 6, it is obvious that the time error between the simulation time and the actual evacuation time is very tiny. The maximum error value is $1.4 \mathrm{~s}$ and the minimum error value is $0.3 \mathrm{~s}$; the value of Pearson product-moment correlation coefficient (PPCC) is adopted to calculate the correlation between the simulation time and the actual evacuation time which is 0.9975 , which denotes that the actual evacuation time of the statistics is in accordance with the simulated evacuation time. Therefore, it can be seen that the simulation method can reflect the whole process of stairs evacuation.

Based on the maximum capacity of the floor, we set up 5 different groups of pedestrian flow rate; the number of each group, respectively, is 50 occupants, 100 occupants, 150 occupants, 200 occupants, and 250 occupants. These groups are set to verify the influence of pedestrian flow rate for the evacuation time and analyze whether the pedestrian flow rate affects the evacuation capacity calculation result and improves the accuracy of analyses result. The relationship between pedestrian flow rate and merging form can be obtained by simulating the process of stairs evacuation. The evacuation time can be obtained in different pedestrian flow rates for the different merging form conditions. The result is shown in Table 1.

In the process of stairway evacuation, when the number of occupants at each floor is constant, the evacuation time in different merging forms is different. It is known that the evacuation time of type 5 merging is minimum after simulation; when the number of occupants is 50 in every floor, the evacuation time of type 5 merging is $114.8 \mathrm{~s}$, the time of type 2 merging is the longest, and the time is $180.8 \mathrm{~s}$. With the increase of the number of occupants on each floor, the evacuation time of the merging will also increase, and the time of evacuation will change with the change of merging form.

According to the results of (9), the fluctuation of value can be got when the pedestrian flow rate changes; the fluctuation of merging form and the evacuation time are fused; we define three groups of the value of $\alpha$, which are $0.3,0.5,0.7$, and calculating the capacity of evacuation, respectively; the capacity of evacuation is described as Table 2. 

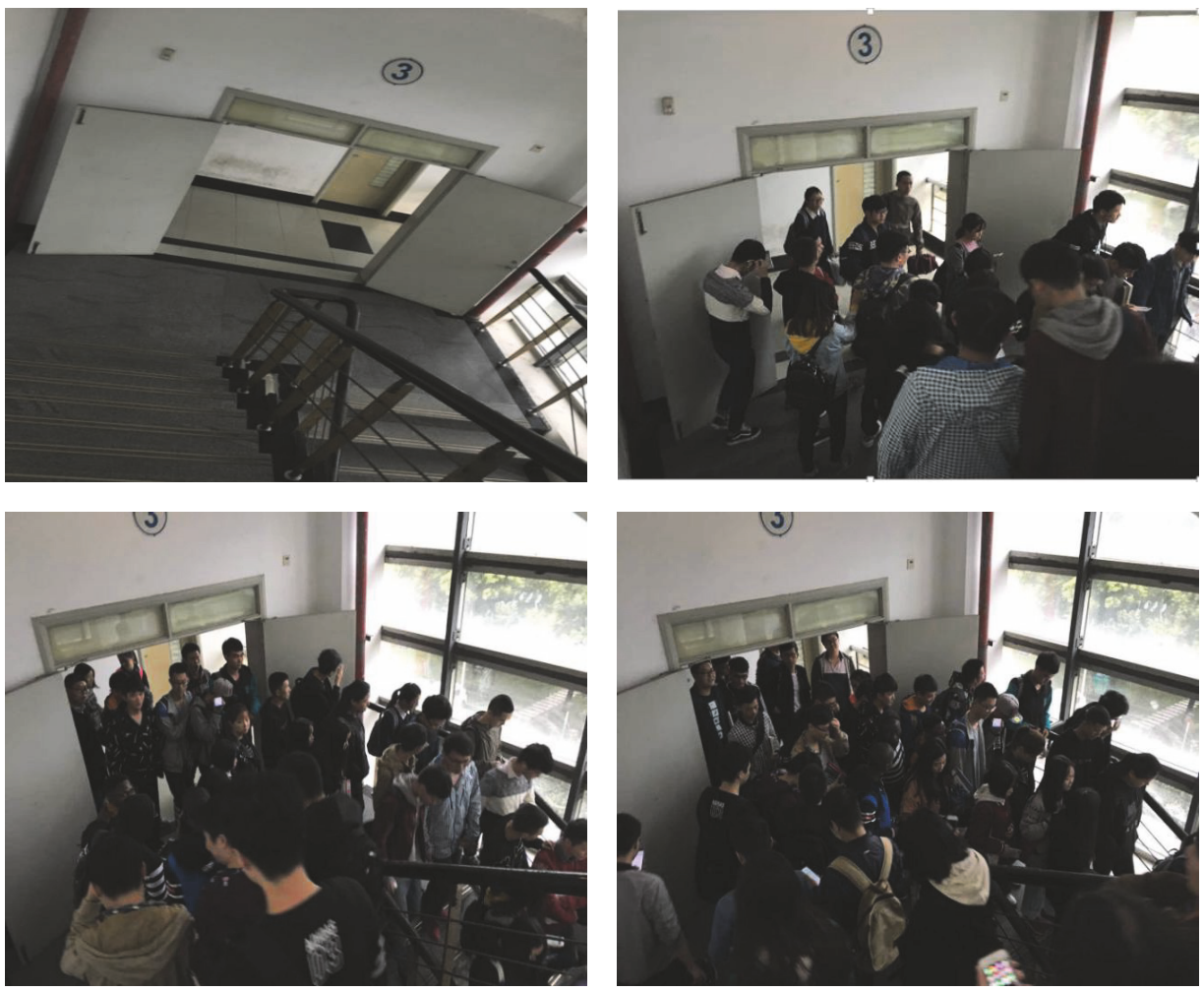

FIGURE 5: The practical evacuation scene in different time for the merging form of type3.

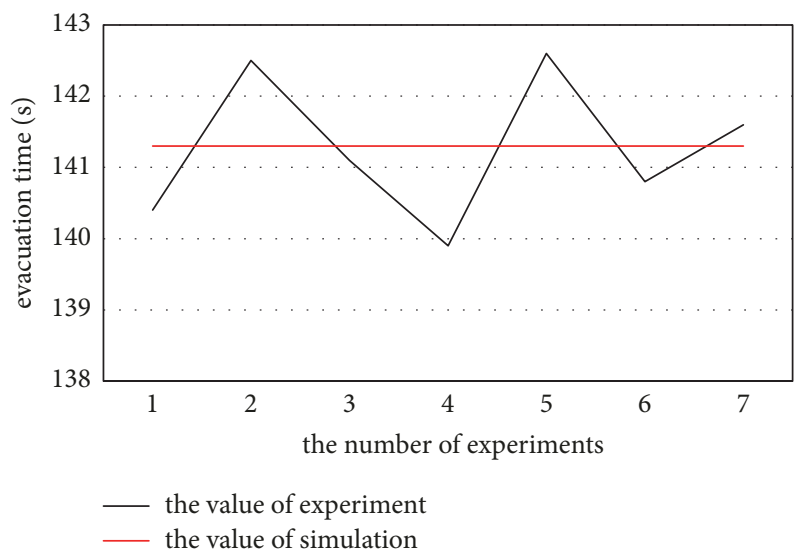

FIgure 6: The difference between experimental evacuation time and simulated evacuation time.

The evacuation capacity will increase as the value of $\alpha$ increases, the change of evacuation ability and the change of $\alpha$ are positive correlation for each merging form by analyzing Table 2. Thus, we take $\alpha=0.5$ as an example to analyze the evacuation capacity of different merging form.

The evacuation capacity of stairs is calculated based on evacuation time and robustness that result can be obtained from Figure 7. According to (9), the capacity value of type1 merging is 2.7443 , the capacity value of type 2 merging is 2.6632 , the capacity value of type 3 merging is 2.6396 , the

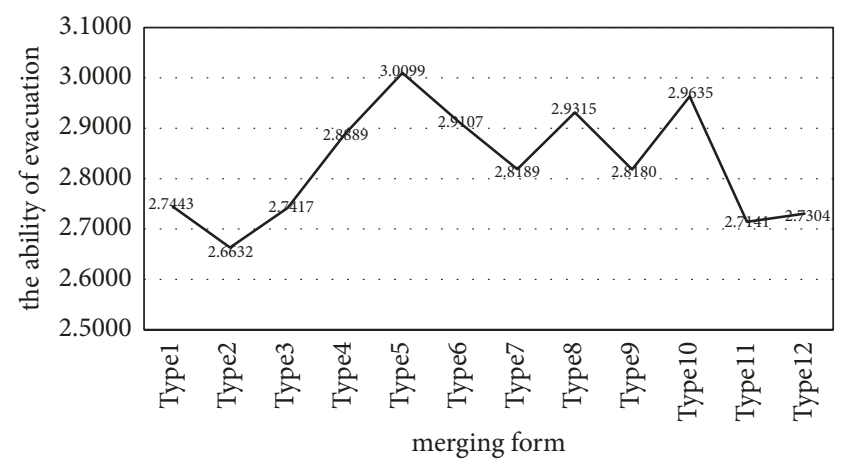

FIGURE 7: The evacuation capacity value for different merging forms.

capacity value of type 4 merging is 2.8889 , the capacity value of type 5 merging is 3.0099 . The capacity value of type 6 merging is 2.9107 . The capacity value of type7 merging is 2.8189 . The capacity value of type 8 merging is 2.9315 . The capacity value of type9 merging is 2.8180 . The capacity value of type10 merging is 2.9635 . The capacity value of typell merging is 2.7141. The capacity value of type12 merging is 2.6325 . According to the capacity values of stairs, the descending order of evacuation capacity of each merging form is shown as type $5>$ type $10>$ type $8>$ type $6>$ type $4>$ type 7 type $9>$ typel $>$ type $3>$ type $12>$ typell $>$ type 2 . The capacity of type 5 merging is the strongest, and the capacity of type 2 merging is the weakest. 
TABLE 1: The evacuation time of different pedestrian flow rate.

\begin{tabular}{|c|c|c|c|c|c|c|}
\hline \multirow{2}{*}{\multicolumn{2}{|c|}{ Evacuation time (s) }} & \multicolumn{5}{|c|}{ Pedestrian flow (per) } \\
\hline & & 50 & 100 & 150 & 200 & 250 \\
\hline \multirow{12}{*}{ Merging form } & Type1 & 119.5 & 233.8 & 351 & 476.8 & 593.3 \\
\hline & Type2 & 180.8 & 355.5 & 522.5 & 680.5 & 879.6 \\
\hline & Type3 & 141.3 & 286 & 433.3 & 575.5 & 722.8 \\
\hline & Type4 & 128.8 & 243.8 & 355.8 & 481.5 & 595.8 \\
\hline & Type5 & 114.8 & 216.8 & 317 & 426.5 & 522.5 \\
\hline & Type6 & 118.3 & 227.5 & 344 & 454.5 & 569 \\
\hline & Type7 & 116 & 219 & 341.3 & 447.8 & 561 \\
\hline & Type8 & 120 & 235 & 340.5 & 455.8 & 564.5 \\
\hline & Type9 & 116.8 & 227.3 & 345.5 & 459 & 570.5 \\
\hline & Type10 & 117.3 & 230.8 & 336.5 & 448.3 & 550.5 \\
\hline & Type11 & 123.8 & 242 & 369.5 & 492.3 & 619.8 \\
\hline & Type12 & 129.8 & 259.8 & 394.3 & 534.3 & 667.3 \\
\hline
\end{tabular}

TABLE 2: The evacuation capacity of different merging form.

\begin{tabular}{|c|c|c|c|c|c|c|c|c|c|c|c|c|c|}
\hline \multirow{2}{*}{$\alpha=0.3$} & $\mathrm{Me}$ & ypel & ype2 & ype3 & Type4 & ype5 & Type6 & Type7 & ype8 & -ype9 & Type10 & ype11 & Type12 \\
\hline & & .6343 & 1.5241 & 6238 & 1.8642 & 365 & 1.8732 & 1.8325 & 8843 & 8217 & 8821 & 6049 & 6147 \\
\hline \multirow{2}{*}{$\alpha=0.5$} & & wne1 & Type2 & Type3 & e4 & e5 & Ty & e7 & e8 & ype9 & 10 & 11 & $\mathrm{e} 12$ \\
\hline & & & 2.6632 & 2.7417 & 2.8889 & 3.0 & 2.9107 & 2.8189 & 2.9315 & 2.8180 & 35 & 2.7141 & .7304 \\
\hline \multirow{2}{*}{$\alpha=0.7$} & & & & & & & & & & & & el1 & \\
\hline & vace & 3.0145 & 2.9136 & 2.9744 & 3.1385 & 3.3771 & 3.2156 & 3.0769 & 3.1793 & 3.0136 & 3.2643 & 2.9356 & 2.9514 \\
\hline
\end{tabular}

\section{Discussion}

By looking up the architectural design criterion, the form of all parallel double running stairs is obtained, the different parallel double running stairs have the different merging form; thus, the merging form is adopted to represent the form of parallel double running stairs. The staircase and exit of the building can be described as Figure 8 .

The agent-based model is adopted to simulate the process of merging; meanwhile, the behavior driving is considered to improve the agent-based model. The evacuation process can be obtained by simulation, and the merging process can be reflected with the stairs pedestrian flow rate. Taking 100 occupants in each floor as an example to demonstrate the process of merging, and when there are 100 occupants in each floor, the evacuation situation of stairs are shown as in Figure 9.

The evacuation rate of stairs is adopted to analyze the process of merging; the evacuation rate can reflect the crowded situation of stair. In this case, the building has 3 floors, the number of stairs is 4 , and there are only two places where merging occurs. The top stairs are defined as stair01 and the bottom of stairs is defined as stair04; stair01 and stair02 are linked by the stairs platform, when the occupants in stairs increase and the evacuation rate of stair01 and stair02 will be influenced by the merging in floor platform. Stair03 and stair04 link the building exit, and the process of merging occurs in the bottom floor platform, but the occupants in bottom floor get close to the building exit, and a part of occupants will leave the building at the start

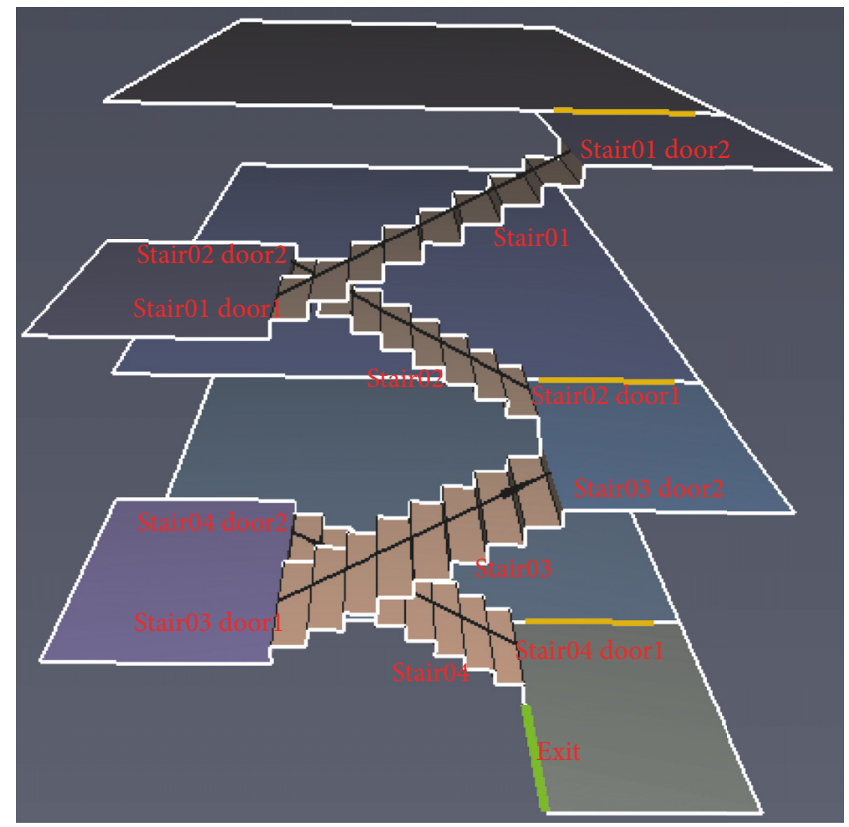

FIGURE 8: The staircase and exit of the building.

of evacuation. Therefore, the number of occupants in the process of merging is less and the time of merging is short; meanwhile, the fluctuation of evacuation rate in stair03 and stair04 is less and only smaller change appears during the evacuation peak. Taking typel merging as an example, the 


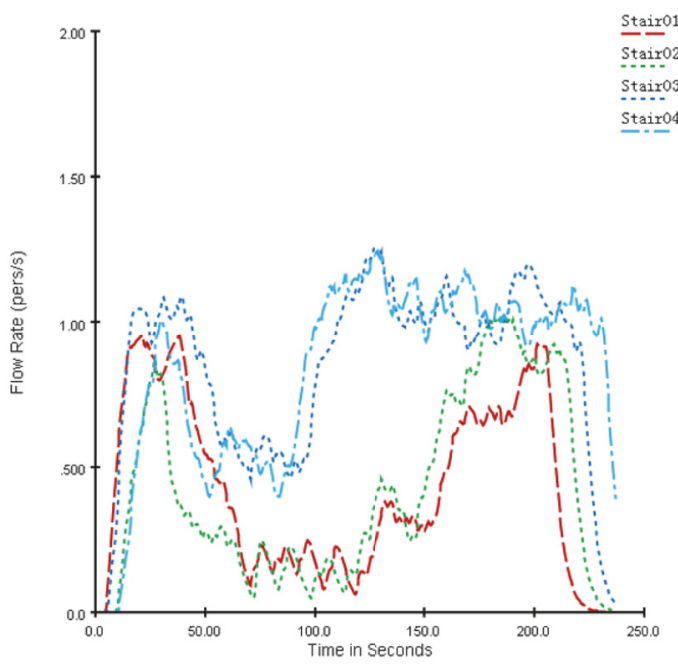

(a)

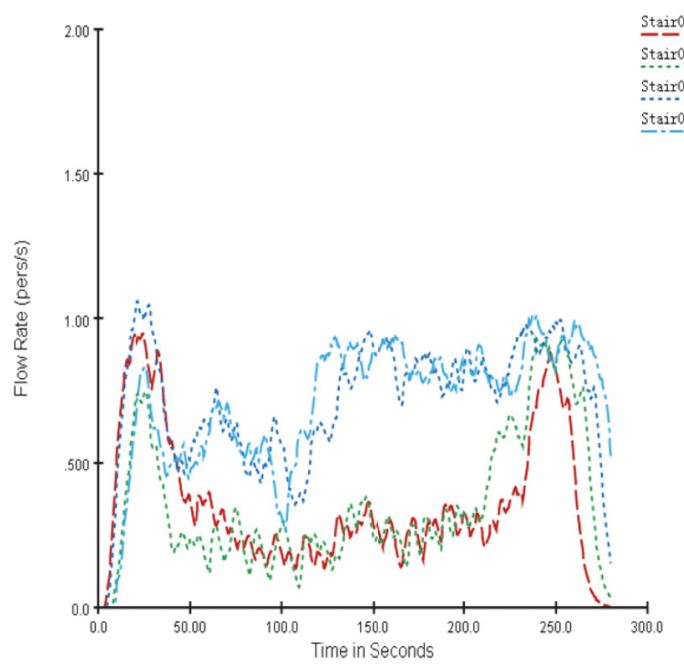

(c)

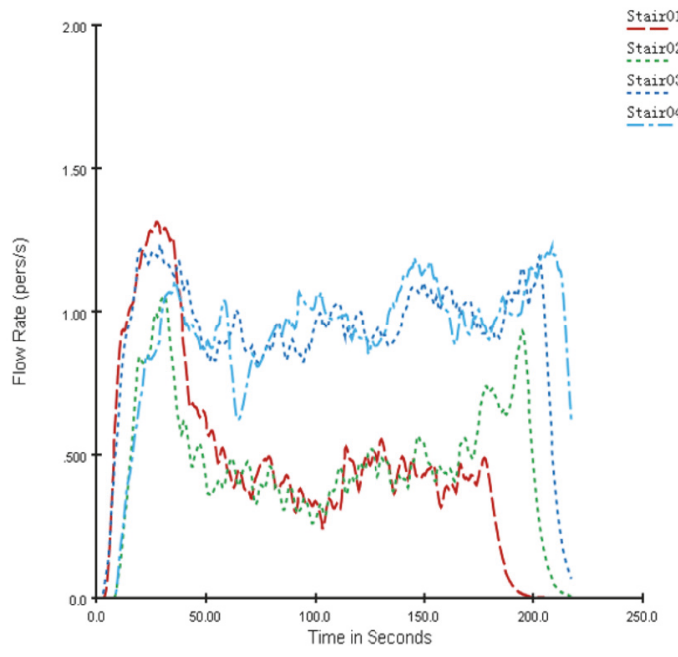

(e)

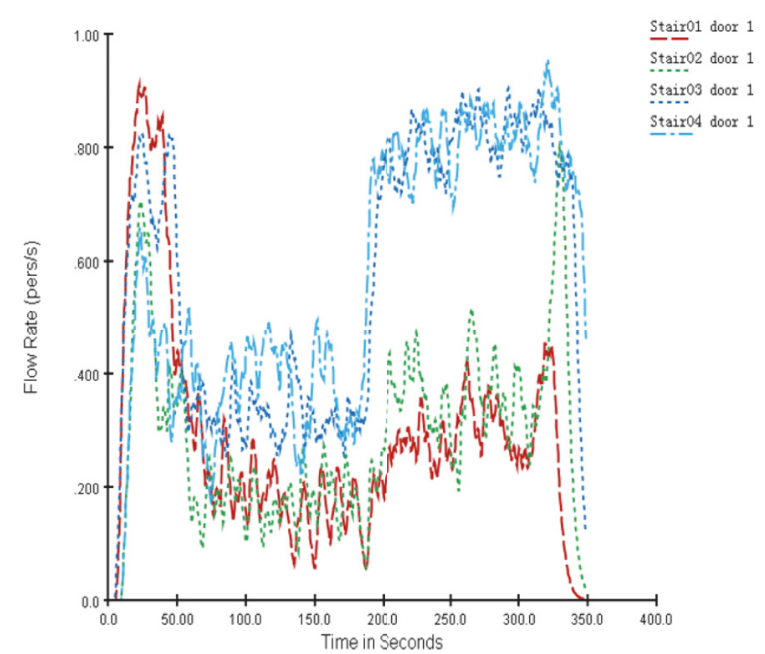

(b)
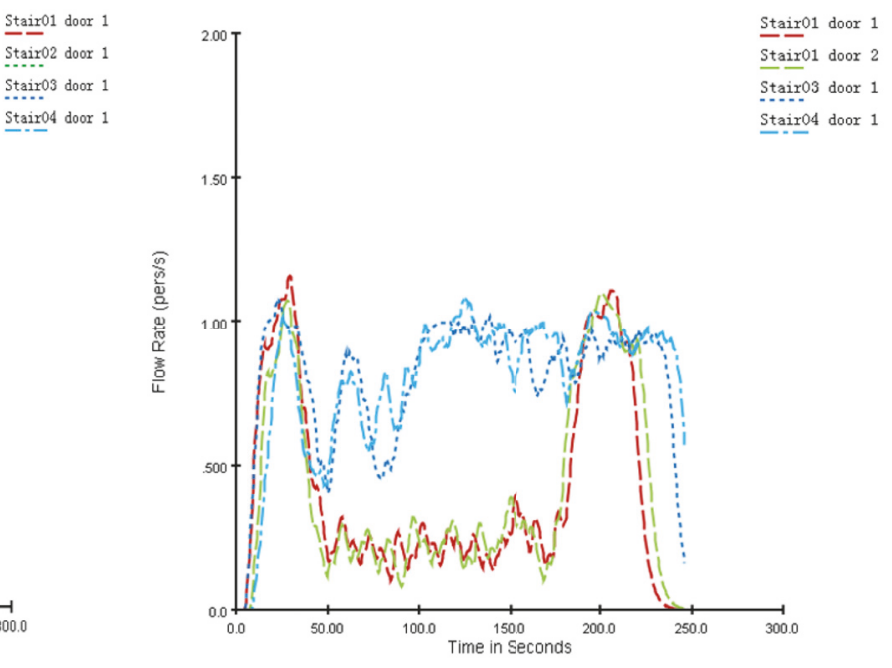

(d)
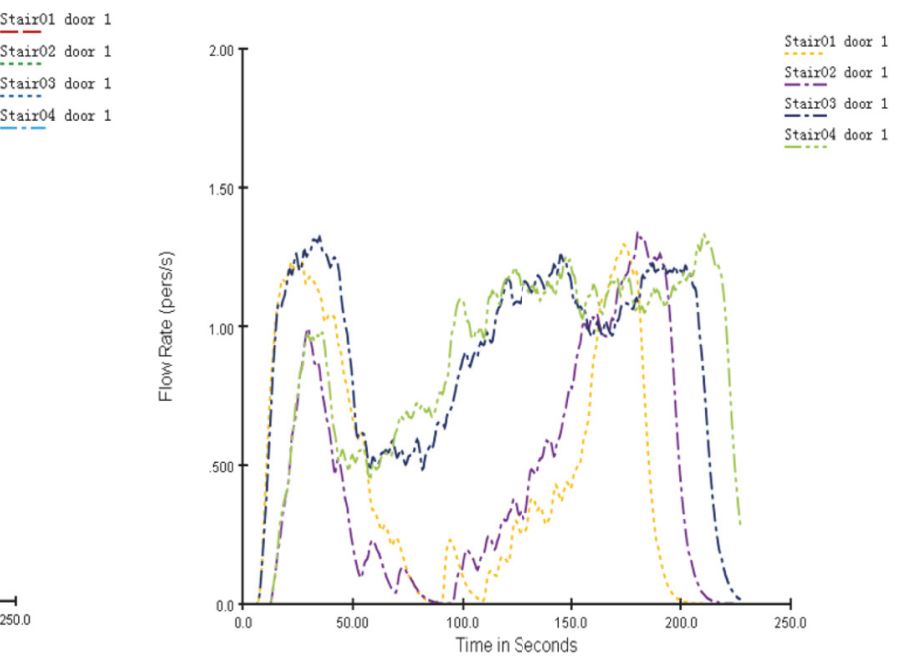

(f)

FIgUre 9: Continued. 


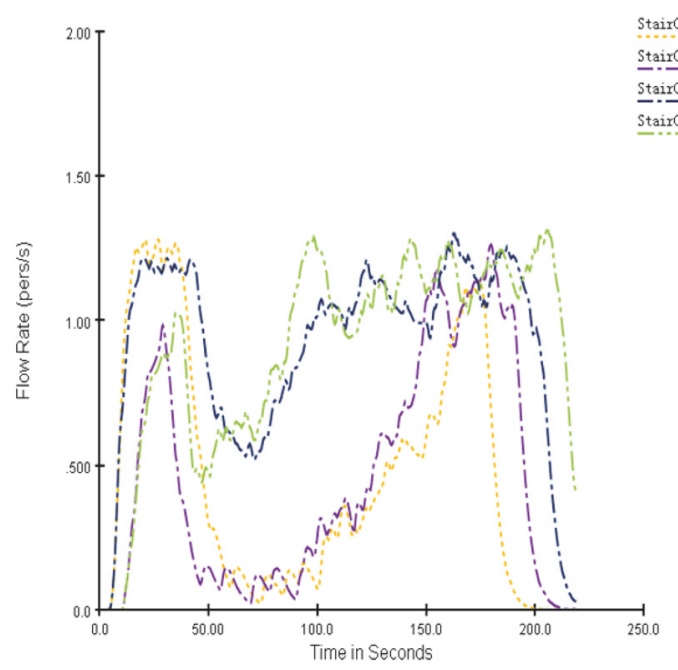

(g)

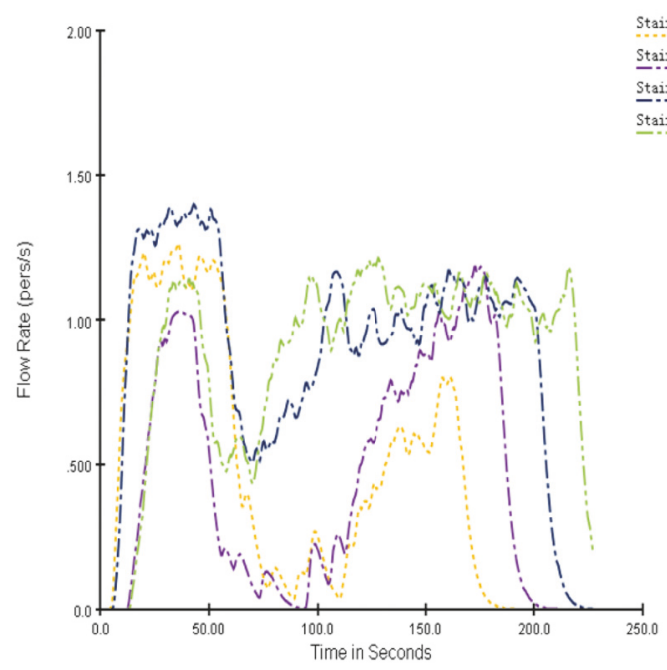

(i)

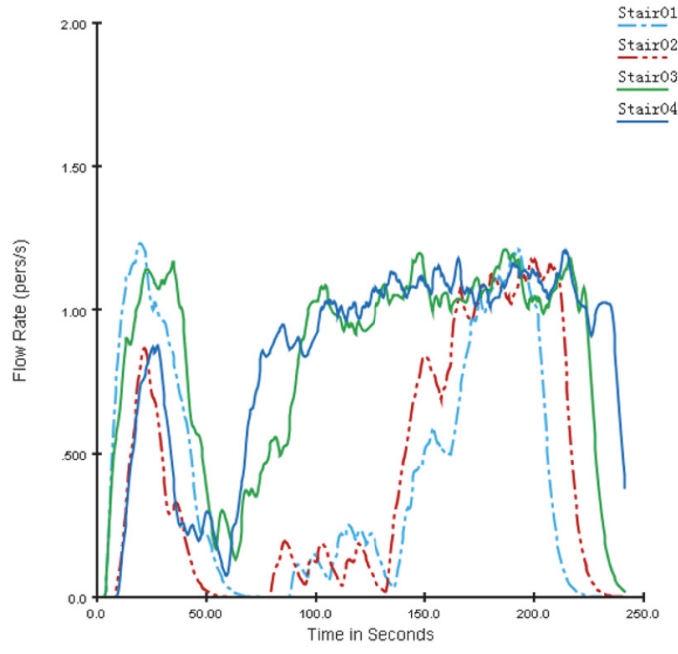

(k)
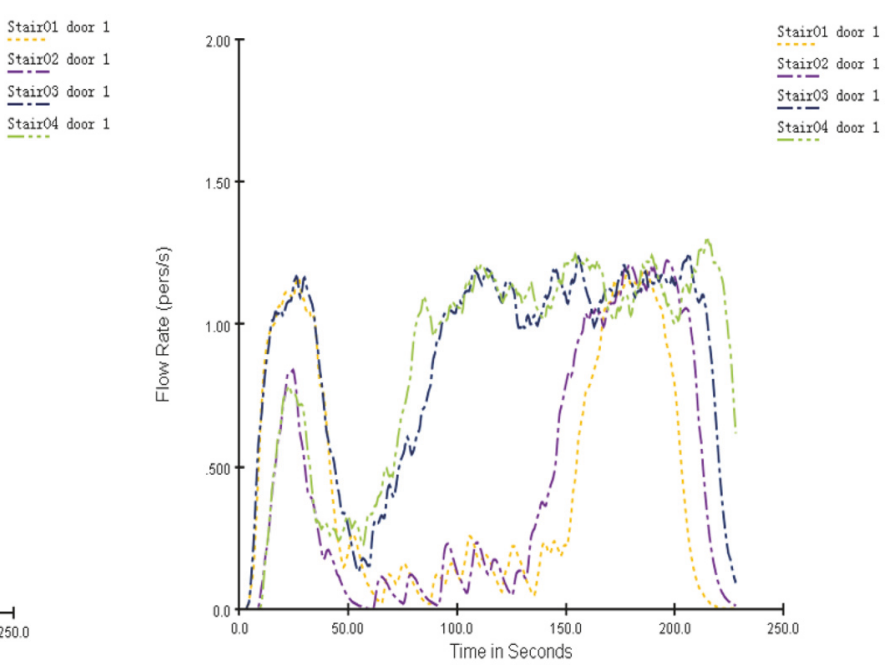

(h)

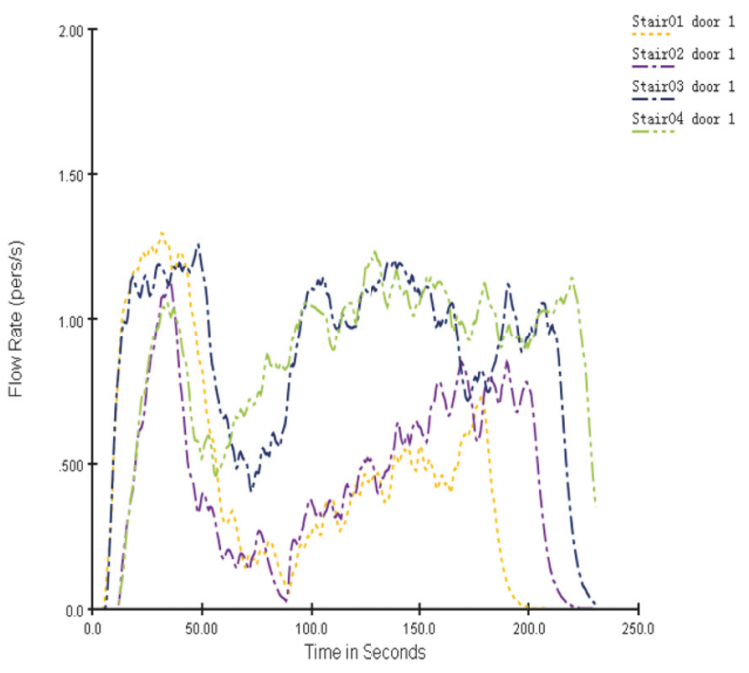

(j)

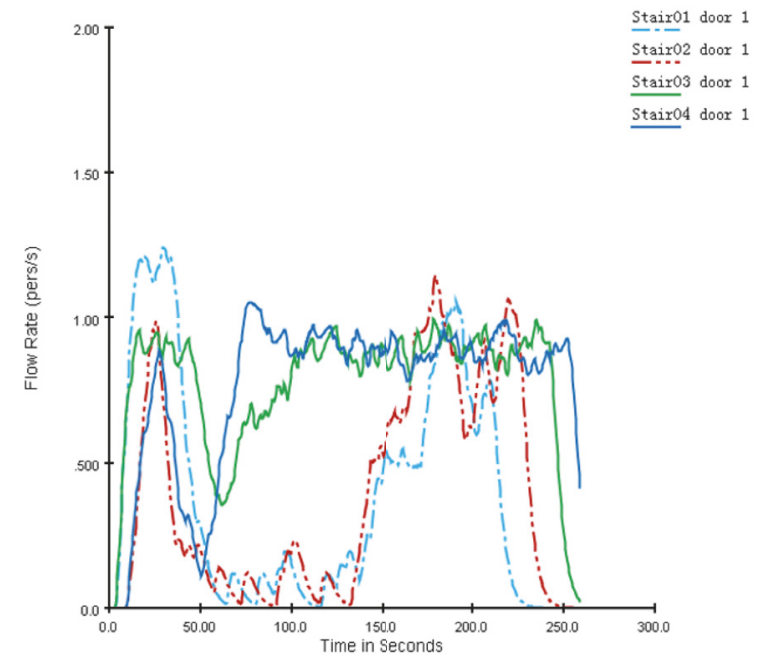

(1)

FIGURE 9: The flow rate of stairs in each merging forms. (a) typel; (b) type2; (c) type3; (d) type4; (e) type5; (f) type6; (g) type7; (h) type8; (i) type9; (j) type10; (k) type11; (l) type12. 
flow rate is less than 0.5 for stair01 and stair02 in evacuation peak in Figure 9, because the merging behavior is more obvious in the evacuation peak, and the merging behavior will cause the evacuation rate to decrease. With the increasing of evacuation time, the flow rate in the bottom floor will decrease in the evacuation peak and then gradually increase and tend to be stable at last in stair03 and stair04. The scale of time in which evacuation rate is less than 0.5 will continue about 120s in typel merging (Figure 9), and the maximum of evacuation rate is more than 1 . Another merging form have the same trend in stairs flow rate with the time increasing, but by comparing the evacuation time, it is obvious that the flow rate influences the evacuation time. Different merging forms have different flow rates. The stronger the merging form of the evacuation capability, the higher the flow rate in process of evacuation. Moreover, stair01 and stair02 have the lower flow rates in the peak. The larger the evacuation time, the longer continuous time in the lower flow rate. What is more, stair03 and stair04 will have larger fluctuation in a merging form which needs more evacuation time.

To sum up, the reason of the difference of evacuation capacity is the merging form. The influence factors of evacuation capacity are the evacuation time and the robustness of the stairs; the difference of merging form will result in the change of evacuation time and robustness of the stairs, such as type 5 (see Figure 9(e)); the evacuation time is the shortest because the merging time is short; meanwhile, the flow rate in each stair is steady in the evacuation process. Because the floor entrance is close to the out stair and the merging zone of stair pedestrian flow and floor pedestrian flow lies in out stair, the merging zone area is not large, the pedestrian can leave the floor platform after merging on a short time, and the pedestrians do not gather in the floor platform. On the contrary, if the floor entrance keeps away from the out stair or the number of floor entrances increases, the merging zone area increases, and the process of merging becomes more complex. The pedestrians gather in the platform as the development of merging, the merging time increases, and the evacuation capacity decreases (see Figures 9(b) and 9(k)).

The ability of evacuation is not only relevant to evacuation time but influenced by the robustness of stairs. Therefore, the evaluation model of stairs merging form is established by fusing the evacuation time and the robustness of stair. The robustness of stairs is denoted by comparing the fluctuation case of stairs evacuation time in different flow, and according to (8), the robustness of different merging forms can be obtained as in Figure 10.

Figure 10 represents the fluctuation trend of stairs; it is obvious that the merging form of type12 has the minimum robustness, and the robustness of type 5 is the largest. Unlike the result of the evacuation time, type 2 spends the longest time in the process of evacuation, but the robustness is not the minimum, the merging form of type1 2 has the minimum robustness, and the evacuation time is not the lowest. However, the new result can be obtained by comparing the robustness and evacuation time, the evacuation time represents the traffic capacity of stair, but the robustness denotes the fluctuation of stair; that is, it represents the sensitive degree of stairs merging form for changing pedestrian

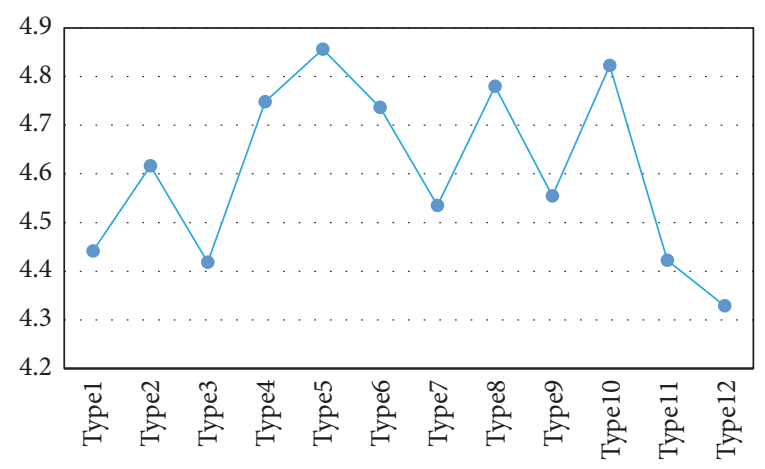

FIGURE 10: The robustness value for different merging forms.

flow. Therefore, the capacity of stairs should consider the robustness.

Through calculating the capacity of stairs, the result shows that evacuation capability of type 5 is the strongest and suitable for large crowd evacuation and architecture if the pedestrian flow rate changes greatly. Fusing the evacuation time and the robustness of stairs, the merging form of type 5 is more suitable for the large scale of evacuation, when flow rate changes greatly, the merging form of type 5 has better stability and lower sensitivity for the pedestrian flow rate, and the evacuation time will not cause too much fluctuation. The merging form of type 2 is very sensitive to the change of pedestrian flow rate. When the pedestrian flow rate changes, the stability of merging form of type 2 is weak.

\section{Conclusion}

Aiming at the question of stairs evacuation, the paper discusses the influence of different merging forms on the time of stairs evacuation. The six kinds of stairs merging form are obtained by looking up criterion, and the agentbased evacuation model is adopted to simulate the process of merging in the stairs evacuation, and the merging behavior is shown in the agent-based model. The agent-based model can simulate the evacuation time, the ability of evacuation of stairs is calculated by the evacuation time and the robustness of stairs, and the evaluation of the ability of evacuation model is established. According to the evaluation model, setting up the stairs evacuation scene by changing the number of occupants in the stairs, the process of stairs evacuation is simulated, and the accuracy of simulation is verified by the experiment. By analyzing the simulation results, the evacuation time of the merging form of type 5 is the shortest, and the robustness of the merging form of type 5 is the strongest, the ability of evacuation of type 5 merging is the best, and the merging form of type 5 is suitable for the evacuation of large pedestrian flow rate. The ability of evacuation of the merging form of type 2 is the worst, with the change of the number of occupants, the robustness of stairs is unstable, and the evacuation time is the longest; therefore, the merging form of type 2 is suitable for the place which has less occupants.

In the process of stairway evacuation, the process of merging will affect the stairs evacuation time. Therefore, the 
next research focus will be on the psychological behavior of occupants in the merging.

\section{Conflicts of Interest}

The authors declare that there are no conflicts of interest regarding the publication of this paper.

\section{Acknowledgments}

Xia-zhong Zheng acknowledges National Natural Science Foundation of China (51379110).

\section{References}

[1] J. Chen, J. Wang, J. Wang, X. Liu, T. Li, and P. Lin, "An experimental study of individual ascent speed on long stairs," Fire Technology, vol. 53, no. 1, pp. 1-18, 2016.

[2] E. Ronchi and D. Nilsson, "Fire evacuation in high-rise buildings: a review of human behavior and modelling research," Fire Science Reviews, vol. 2, no. 1, article 7, 2013.

[3] T. Sano, E. Ronchi, Y. Minegishi, and D. Nilsson, "A pedestrian merging flow model for stair evacuation," Fire Safety Journal, vol. 89, pp. 77-89, 2017.

[4] N. Ding, H. Zhang, T. Chen, and P. B. Luh, "Stairs evacuation simulation based on cellular automata considering evacuees' walk preferences," Chinese Physics B, vol. 24, no. 6, pp. 687-693, 2015.

[5] M. J. Spearpoint, "Network modeling of the Station Nightclub fire evacuation," Journal of Fire Protection Engineering, vol. 22, no. 3, pp. 157-181, 2012.

[6] J. Joo, N. Kim, R. A. Wysk et al., "Agent-based simulation of affordance-based human behaviors in emergency evacuation," Simulation Modelling Practice and Theory, vol. 32, no. 2, pp. 99115, 2013.

[7] J. Ma, S. M. Lo, and W. G. Song, "Cellular automaton modeling approach for optimum ultra high-rise building evacuation design," Fire Safety Journal, vol. 54, no. 6, pp. 57-66, 2012.

[8] R. Alizadeh, "A dynamic cellular automaton model for evacuation process with obstacles," Safety Science, vol. 49, no. 2, pp. 315-323, 2011.

[9] X. Guo, J. Chen, S. You, and J. Wei, "Modeling of pedestrian evacuation under fire emergency based on an extended heterogeneous lattice gas model," Physica A: Statistical Mechanics and its Applications, vol. 392, no. 9, pp. 1994-2006, 2013.

[10] T. Ezaki, D. Yanagisawa, K. Ohtsuka, and K. Nishinari, "Simulation of space acquisition process of pedestrians using Proxemic Floor Field Model," Physica A: Statistical Mechanics and its Applications, vol. 391, no. 1-2, pp. 291-299, 2011.

[11] X. Zheng, T. Zhong, and M. Liu, "Modeling crowd evacuation of a building based on seven methodological approaches," Building and Environment, vol. 44, no. 3, pp. 437-445, 2009.

[12] Y. Ding, L. Yang, F. Weng, Z. Fu, and P. Rao, "Investigation of combined stairs elevators evacuation strategies for high rise buildings based on simulation," Simulation Modelling Practice and Theory, vol. 53, pp. 60-73, 2015.

[13] Y. Zeng, W. Song, S. Jin, R. Ye, and X. Liu, "Experimental study on walking preference during high-rise stair evacuation under different ground illuminations," Physica A: Statistical Mechanics and its Applications, vol. 479, pp. 26-37, 2017.
[14] S. A. Lavender, G. E. Hedman, J. P. Mehta, P. A. Reichelt, K. M. Conrad, and S. Park, "Evaluating the physical demands on firefighters using hand-carried stairs descent devices to evacuate mobility-limited occupants from high-rise buildings," Applied Ergonomics, vol. 46 Pt A, no. 3, artilcle 96, 2015.

[15] W. Lei, A. Li, R. Gao, and X. Wang, "Influences of exit and stairs conditions on human evacuation in a dormitory," Physica A: Statistical Mechanics and its Applications, vol. 391, no. 24, pp. 6279-6286, 2012.

[16] A. R. Larusdottir and A. S. Dederichs, "Evacuation of children: movement on stairs and on horizontal plane," Fire Technology, vol. 48, no. 1, pp. 43-53, 2012.

[17] E. Kuligowski, R. Peacock, E. Wiess, and B. Hoskins, "Stairs evacuation of older adults and people with mobility impairments," Fire Safety Journal, vol. 62, no. 4, pp. 230-237, 2013.

[18] W. Li, Y. Li, P. Yu et al., "Modeling, simulation and analysis of the evacuation process on stairs in a multi-floor classroom building of a primary school," Physica A: Statistical Mechanics and its Applications, vol. 469, pp. 157-172, 2016.

[19] E. Ronchi, P. A. Reneke, and R. D. Peacock, "A conceptual fatigue-motivation model to represent pedestrian movement during stairs evacuation," Applied Mathematical Modelling, vol. 40, no. 7-8, pp. 4380-4396, 2016.

[20] Y. Qu, Z. Gao, Y. Xiao, and X. Li, "Modeling the pedestrian's movement and simulating evacuation dynamics on stairs," Safety Science, vol. 70, no. 70, pp. 189-201, 2014.

[21] A. K. Silverman, R. R. Neptune, E. H. Sinitski, and J. M. Wilken, "Whole-body angular momentum during stairs ascent and descent," Gait \& Posture, vol. 39, no. 4, pp. 1109-1114, 2014.

[22] M. Delin, J. Norén, E. Ronchi, K. Kuklane, A. Halder, and K. Fridolf, "Ascending stairs evacuation: walking speed as a function of height," Fire and Materials, 2017.

[23] E. R. Galea, G. Sharp, and P. J. Lawrence, "Investigating the representation of merging behavior at the floor-stairs interface in computer simulations of multi-floor building evacuations," Journal of Fire Protection Engineering, vol. 18, no. 8, pp. 291-316, 2008.

[24] J. Shi, A. Ren, and C. Chen, "Agent-based evacuation model of large public buildings under fire conditions," Automation in Construction, vol. 18, no. 3, pp. 338-347, 2009.

[25] V. Dossetti, S. Bouzat, and M. N. Kuperman, "Behavioral effects in room evacuation models," Physica A: Statistical Mechanics and its Applications, vol. 479, pp. 193-202, 2017.

[26] "Code for fire protection design of tall buildings, GB 50045-95," 2005, http://www.doc88.com/p-999310843404.html.

[27] “Code for design of civil buildings, GB50352-2005125," 2005, http://www.doc88.com/p-63449296045.html.

[28] H. Sun, A. Zhang, and J. Cao, "Earthquake response analysis for stairs about frame structure," Engineering Failure Analysis, vol. 33, no. 7, pp. 490-496, 2013.

[29] T. Sano, E. Ronchi, Y. Minegishi et al., "Modelling pedestrian merging in stair evacuation in multi-purpose buildings," Simulation Modelling Practice \& Theory, vol. 85, 2018.

[30] M. Schultz, S. Lehmann, and H. Fricke, "A discrete microscopic model for pedestrian dynamics to manage emergency situations in airport terminals," in Pedestrian and evacuation dynamics 2005, N. Waldau, P. Gattermann, H. Knoflacher, and M. Schreckenber, Eds., pp. 369-375, Springer, Berlin, Germany, 2007.

[31] A. Braun, B. E. Bodmann, and S. R. Musse, "Simulating virtual crowds in emergency situations," in Proceedings of the the ACM 
symposium on Virtual Reality Software and Technology VRST, pp. 244-252, Monterey, Calif, USA, November 2005.

[32] A. Kirchner and A. Schadschneider, "Simulation of evacuation processes using a bionics-inspired cellular automaton model for pedestrian dynamics," Physica A: Statistical Mechanics and its Applications, vol. 312, no. 1-2, pp. 260-276, 2002.

[33] S. Bandini, M. L. Federici, S. Manzoni, and G. Vizzari, “Towards a methodology for situated cellular agent based crowd simulations," in Lecture Notes in Computer Science, O. Dikenelli, M.P. Gleizes, and A. Ricci, Eds., vol. 3963, pp. 203-220, Springer, Berlin, Germany, 2006.

[34] X. Pan, C. S. Han, K. Dauber, and K. H. Law, "A multiagent based framework for the simulation of human and social behaviors during emergency evacuations," AI and Society, vol. 22, no. 2, pp. 113-132, 2007.

[35] N. Pelechano, J. M. Allbeck, and N. I. Badler, "Controlling individual agents in high-density crowd simulation," in Proceedings of the 2007 ACM SIGGRAPH / Eurographics symposium on computer animation, D. Metaxas and J. Popovic, Eds., pp. 99108, San Diego, Calf, USA, 2007.

[36] M. C. Toyama, A. L. Bazzan, and R. da Silva, "An agent-based simulation of pedestrian dynamics: from lane formation to auditorium evacuation," in Proceedings ofthe fifth international joint conference on autonomous agents and multiagent systems, pp. 108-110, Hakodate, Japan, May 2006.

[37] https://www.thunderheadeng.com/. 


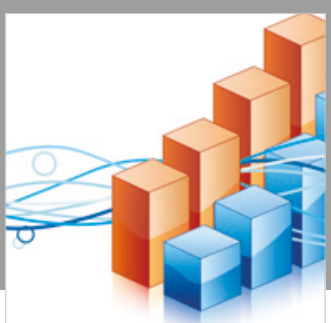

Advances in

Operations Research

\section{-n-m}
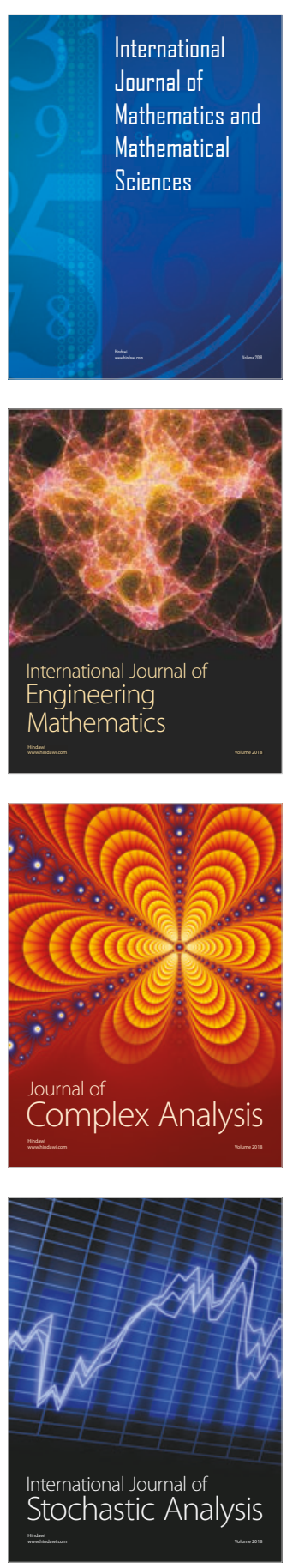
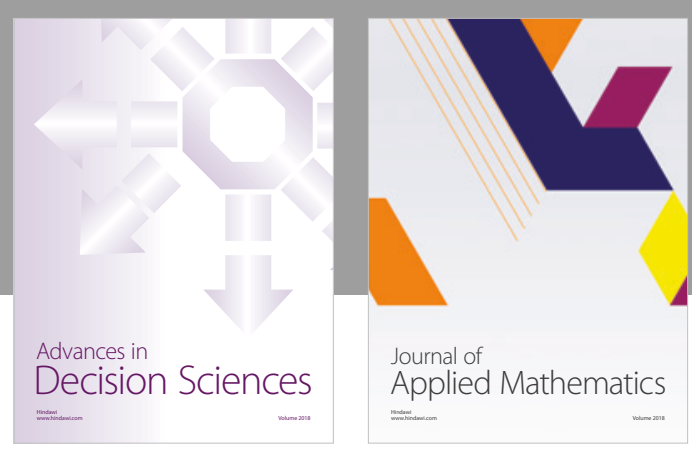

Journal of

Applied Mathematics
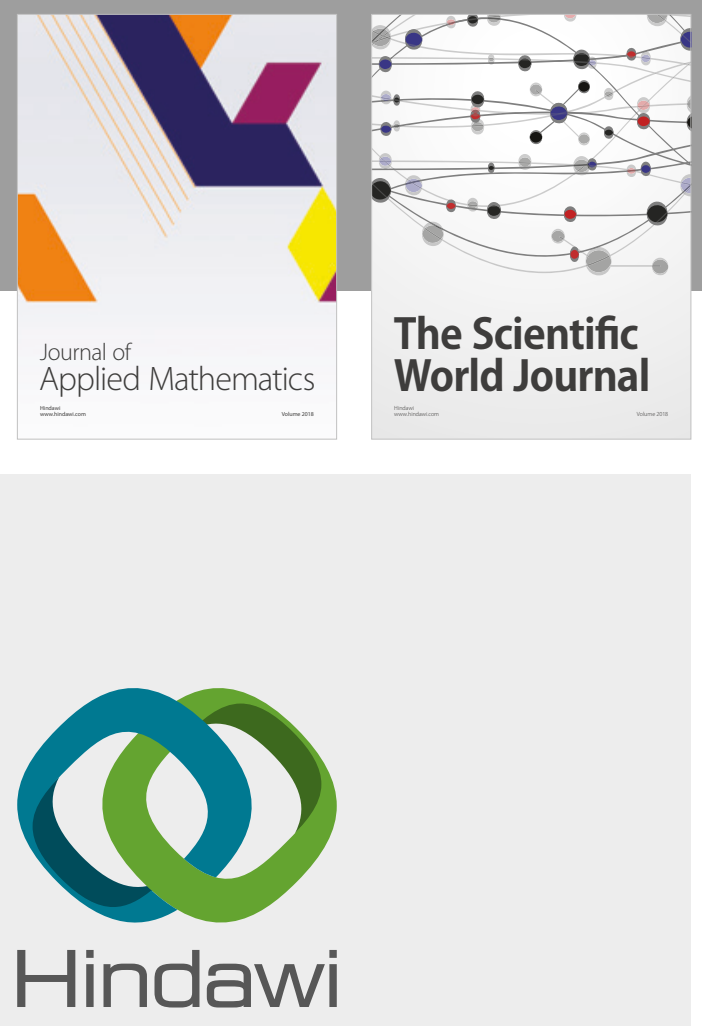

Submit your manuscripts at

www.hindawi.com

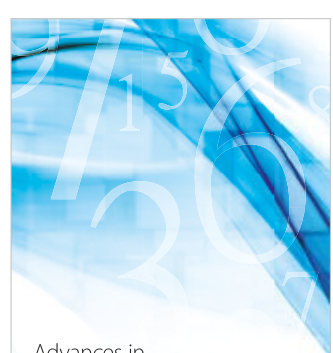

Advances in
Numerical Analysis
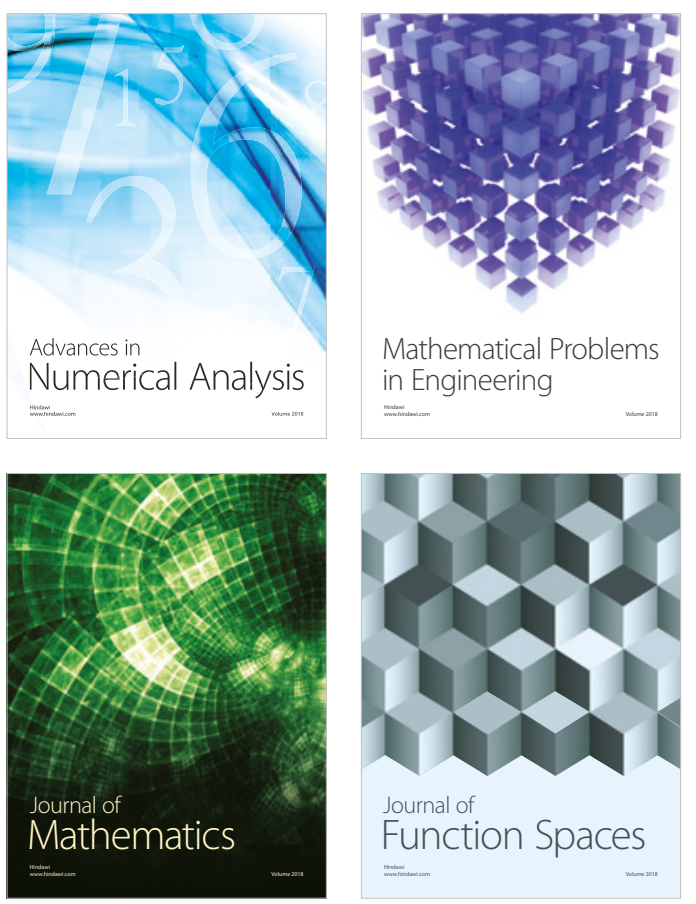

Mathematical Problems in Engineering

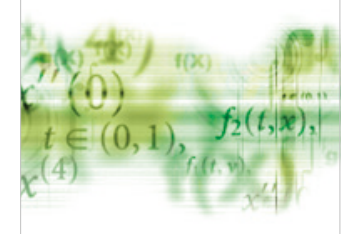

International Journal of

Differential Equations

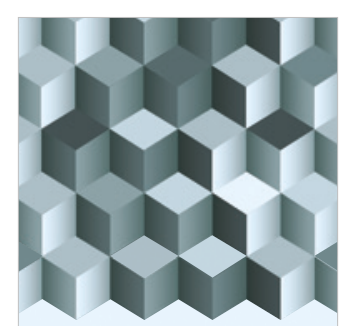

Journal of

Function Spaces

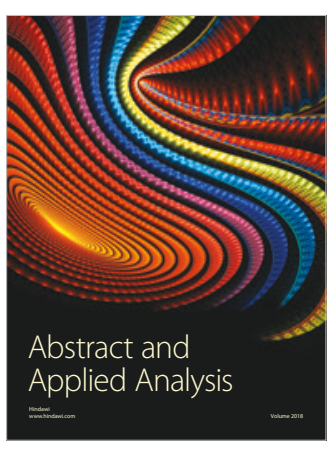

The Scientific

World Journal

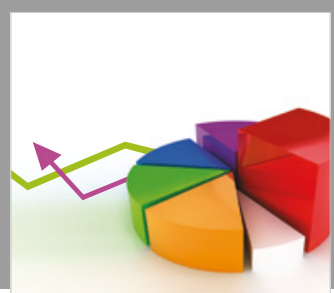

Journal of

Probability and Statistics
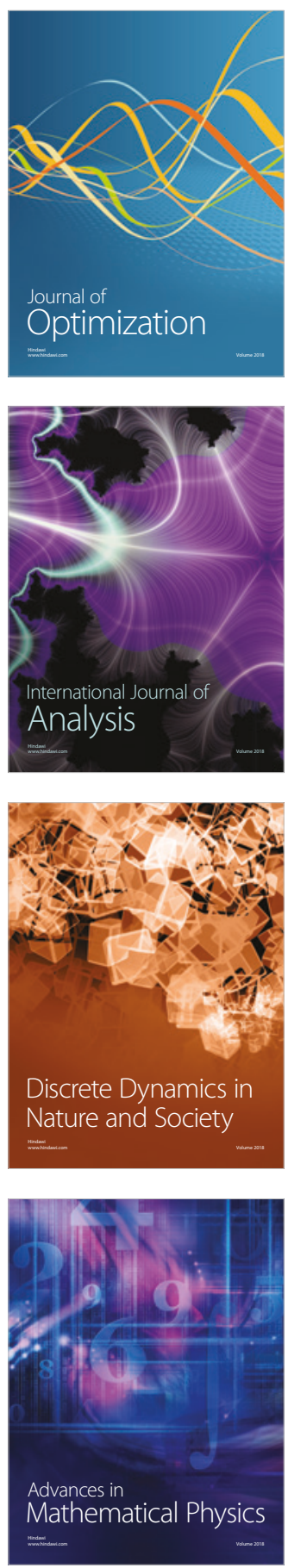